\title{
A Comparative Review of Two Engineering Economics Sections: One Tradi- tional and One Online
}

\section{Dr. Joseph Hubert Wilck IV, East Carolina University}

Dr. Joseph Wilck received a Ph.D. from Pennsylvania State University in Industrial Engineering and Operations Research, and a B.S. and M.S. from Virginia Tech in Industrial and Systems Engineering. Dr. Wilck is a registered professional engineer, vice president of Student Development for the Institute of Industrial Engineers (IIE), and a member of INFORMS, ASEE, INCOSE, APICS, IEEE, and ASEM. Dr. Wilck's research has been sponsored by NSF, DOE, ORNL, and industrial partners. Dr. Wilck has held a faculty position at the University of Tennessee, Knoxville. He is currently an assistant professor of Engineering at East Carolina University.

\section{Dr. Paul J. Kauffmann P.E., East Carolina University}

Dr. Paul J. Kauffmann is a professor and former chair in the Department of Engineering at East Carolina University. His industry career included positions as Plant Manager and Engineering Director. Dr. Kauffmann received a B.S. in Electrical Engineering and MENG in Mechanical Engineering from Virginia Tech. He received his Ph.D. in Industrial Engineering from Penn State and is a registered Professional Engineer in Virginia and North Carolina. 


\title{
A Comparative Review of Two Engineering Economics Sections: One Traditional and One Online
}

\begin{abstract}
This paper analyzes success in meeting learning objectives in two sections of an undergraduate engineering economics course where the professor, course schedule (day-to-day), lectures, assignments, and assessments were constant throughout the semester. The only difference is the online nature of one section and the face to face, traditional approach of the other. The results indicate that the two sections performed similarly for almost all course topics, student assessment of learning objectives and student outcomes, and final grades.
\end{abstract}

\section{Introduction}

As the quality and speed of internet systems and software have developed over the last several years, distance education has evolved to primarily an online delivery mode. The anticipated importance and central role of wide spread online engineering education can be seen by the formation of the Sloan Consortium and its focus on the study of quality, scale, and breadth of online learning $^{1}$. A diverse literature is available to document the breadth of online engineering courses available and studied. Representative examples include engineering graphics ${ }^{2}$, power systems $^{3}$, introduction to engineering ${ }^{4}$, and thermodynamics ${ }^{5}$. Online graduate programs are also well represented in the literature as evidenced by examples on traditional engineering graduate areas such as Whiteman ${ }^{6}$, who surveys online mechanical engineering masters programs, and nontraditional engineering areas such as engineering management ${ }^{7}$.

While online courses have grown as a significant and viable element of higher engineering education $^{8}$, this has not yet led to a significant increase in engineering degrees granted. Recent National Science Foundation (NSF) data notes, the number of engineering undergraduates supplying the engineering workforce remains level as the national need for engineers increases ${ }^{9}$.

Studies continue to validate the effectiveness of online learning. For example, a recent study by the Department of Education ${ }^{10}$ found that students learned more from online courses compared to the traditional face to face classroom method. However, this study also found that students learning improved more when multiple methods were employed combining features of face to face instruction with online methods. Peercy and Cramer ${ }^{11}$ recently emphasized that this issue of the use of technology, whether in an online, face to face, or hybrid context, holds great potential to improve the quality of instruction in the present world of declining financial resources for education. They further emphasize the importance of educational research and the exploration of multiple approaches to teaching with technology from completely online distance learning to minimal use of technology to hybrid methods.

Recently the question of distance education course format impacting affective (satisfaction) and cognitive (knowledge acquisition) learning has been explored. Mackey and Freyburg ${ }^{12}$ found that although cognitive learning in a graduate engineering online course was comparable with the face to face version of the course, participation and social interaction was the most important 
factor influencing affective learning. They recommend consideration of methods to enhance social presence to improve the combined learning experience and make distance learning more enjoyable for students. A second study of an online engineering economics course had similar findings in that students expressed dissatisfaction with the lack of social interaction in a fully online course ${ }^{13}$.

\section{Research Study Motivation and Focus}

The origin of our study is based in a solidly pragmatic perspective. Similar to one of the key motivations noted by the Peercy and Cramer ${ }^{11}$, our engineering program must explore cost effective ways to increase course availability from several perspectives:

- Although many students are able to take courses in the semesters planned when multiple sections are available, there is also a significant number who are off schedule and need "trailing" sections. Unfortunately, timing of face to face sections may conflict with other needed courses and online versions offer scheduling flexibility which is impossible for traditional sections.

- Faculty resources trail the numbers of students in the program. Online courses hold the potential for use of part time faculty, who are working during standard face to face hours, to manage a course and the content is fixed along with the learning outcomes. This promotes the likelihood or reducing learning variability with potentially inexperienced faculty.

Consequently, we selected engineering economics as the first trial course for online learning and identified several research questions supporting contributions to a number of the issues noted in the current literature discussed above:

- Can we document comparative learning outcomes between the online and face to face learning environments?

- Can the online course format adapt to use the ABET assessment methods employed in the face to face sections?

- Is the issue of affective learning a concern and what strategies can improve this factor?

- What technologies and formats are effective in delivering this course?

There are many recent and ongoing studies of engineering economics education within the literature. For example:

- A study was conducted comparing the principles of engineering economics to the principles of engineering mechanics and how students fared when taking one class before the other ${ }^{14}$.

- A discussion of the importance and significance of teaching and course structure of undergraduate engineering economics ${ }^{15,16}$.

- A discussion of the future of engineering economics that includes increased incorporation of spreadsheet analysis while limiting traditional engineering economics topics ${ }^{17,18}$.

- A discussion for online (distance education) of engineering economics ${ }^{19}$, with corresponding studies for the structure of undergraduate ${ }^{20}$ and graduate ${ }^{21}$ courses.

The paper presented here differs from the above studies in that it provides a side-by-side comparison of two sections, one face to face and one traditional, with results including final 
grades, learning objectives, and student outcomes. The next section begins examination of these questions with an overview of how the two sections of engineering economics were structured.

\section{Methodology- Course and Section Structure}

Every effort was made to keep the two sections consistent in as many areas as possible with the obvious exception of the delivery mode. The face to face section held class sessions on Tuesday and Thursday from 2:00PM-3:15PM and had 37 students. The online section had 27 students and held Centra (online chat/ white board system) Q\&A sessions at 6:00PM on Tuesday and Wednesday with half the class targeted to each time period to assure manageable numbers. Blackboard was the course management system for both sections and all assignments were submitted online through the assignment feature. Other consistent factors include the same instructor, identical PowerPoint notes provided, identical homework assignments, consistent weekly topical schedule, textbook, and online quizzes using a lockdown browser (Respondus). The primary difference was that the face to face section had a live lecture and the online section had specifically made videos produced with Camtasia screen capture software.

In general, most weeks covered one chapter in the text. The general sequence of activities involved:

- Coverage of course topics either by lecture or by video using consistent power point slides. Figure 1 provides a screen capture of a typical video.

- For the online section, Centra chat / white board sessions were held on Tuesday and Wednesday. An example screen capture is shown in Figure 2. These sessions were archived for possible future access by students.

- An online, self-evaluation quiz for each chapter was available from Thursday to Sunday night. The quiz system presented approximately 12-15 short answer and computational problems randomly selected from a test bank. They simulated test questions and covered important topics from each chapter. Students had two attempts and were provided correct answers for missed questions. The quizzes employed a "lockdown" browser system which did not allow access to outside software such as email or websites.

- Homework assignments were due in PDF format on blackboard by Sunday at midnight.

- Tests (two and a final exam) were conducted in a face to face format for both sections.

Results of analysis of survey questions and final exam questions are discussed in the next section.

\section{Results}

This section examines results from the two sections using two data sets: student surveys and final exam questions or specific assignments. For the online section, several questions specific to the online experience are also examined. To provide context, final grades are discussed first. Overall, the average final grade for the face to face section was 79.7 and 78.1 for the online section. Figure 3 presents the histogram of the final grade distribution and shows that the online section had a higher percentage of final grades below 60 with 3 of 27 compared to 2 of 36 for the face to face section. On the other end of the spectrum, over $17 \%$ of the face to face section had a grade higher than 90 compared to $11 \%$ for the online section. Although not significant, Figure 3 shows a slight but consistent pattern of lower scores from students in the online section. This indicates the theme of lesser satisfaction with the online course noted by earlier references ${ }^{12,13}$. 


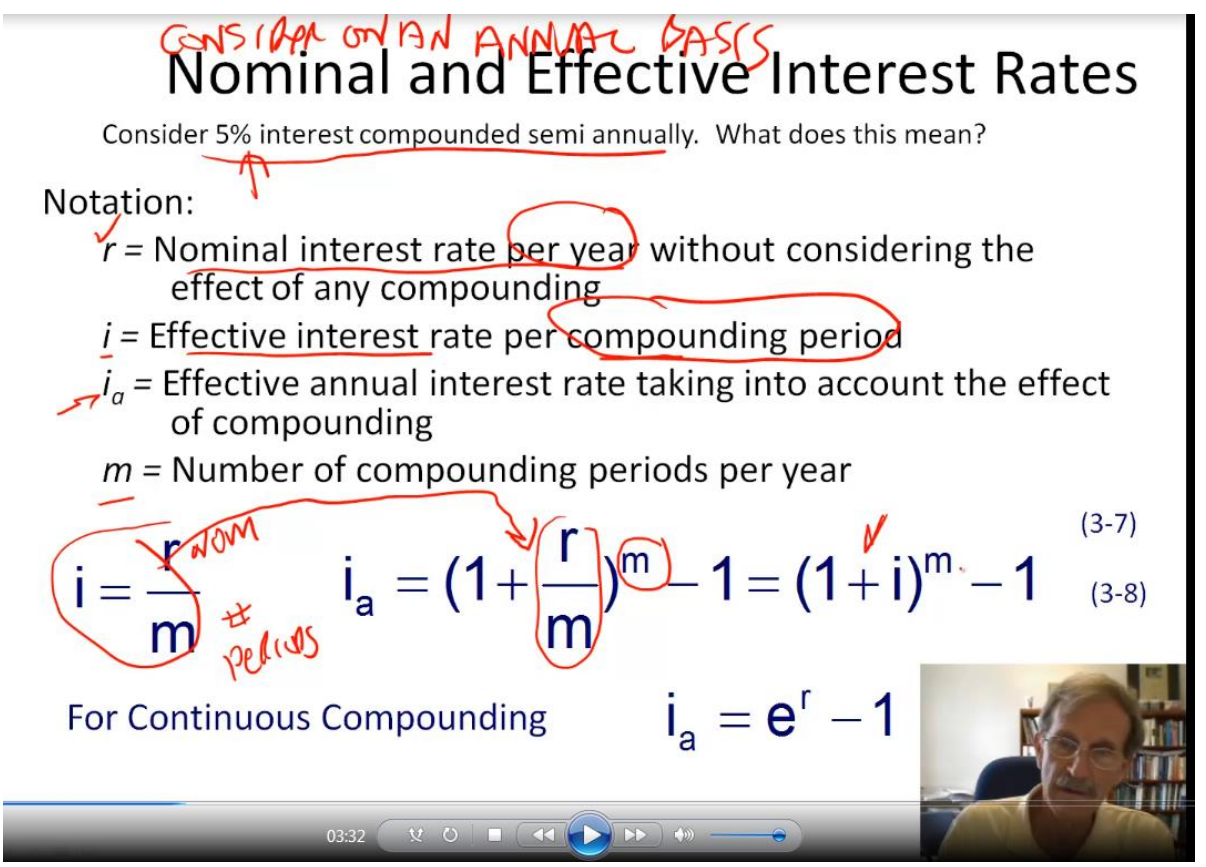

Figure 1: Example of Online Video Lecture from Camtasia.

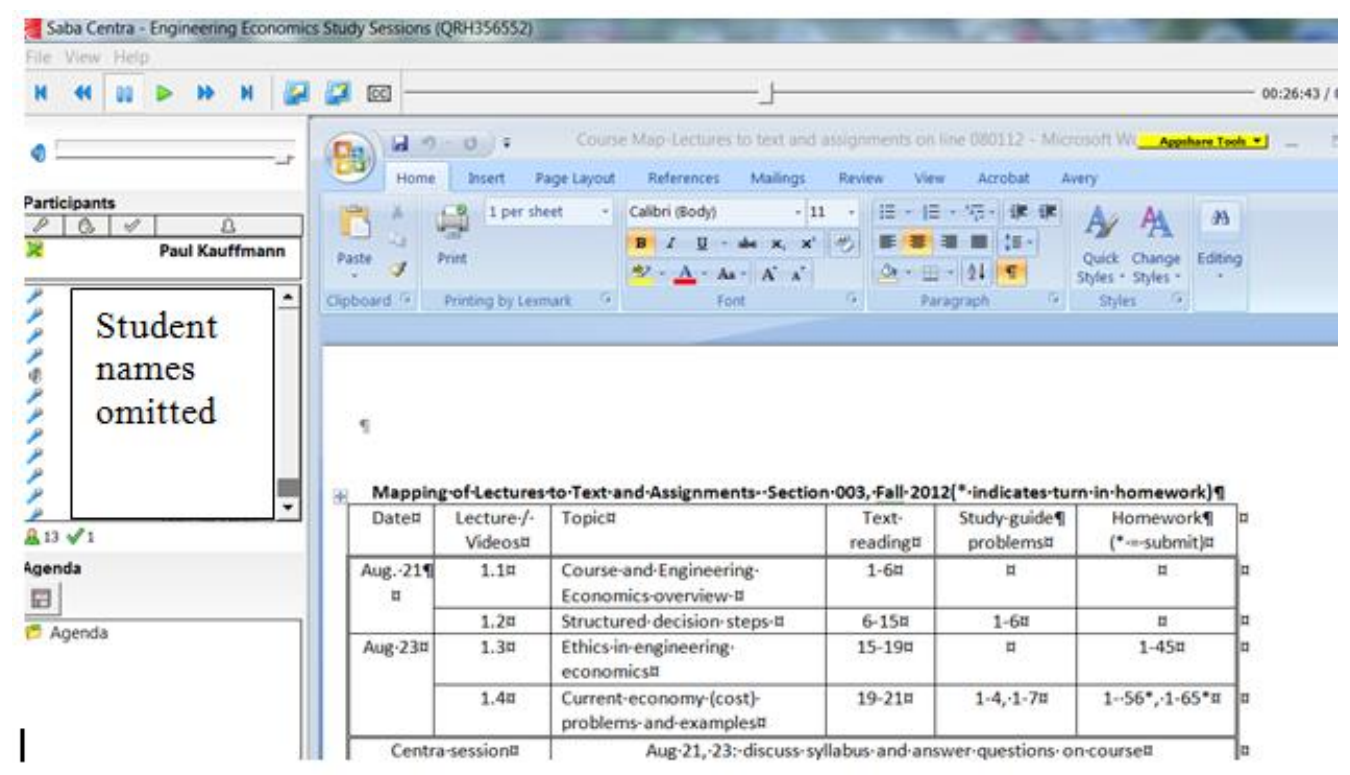

Figure 2: Centra Chat Session Screen Capture. 
Table 1 presents the questions which were completed by the students prior to the final exam. On the left side, the questions represent the specific learning objectives for the course. For the learning objective questions:

- The first nine of these were also evaluated by specific, quantitative, embedded questions from the final exam and the survey.

- Learning objectives 10-13 were evaluated by specific assignments and the survey. The course is classified as a "Writing Intensive" course per university requirements and required completion of three writing assignments.

a. Two were individual assignments covering a twelve page research paper on the grand challenges of engineering and a business memo analyzing a fixed/ variable cost problem.

b. The second memo was produced by a team of three or four students analyzing ratios from a set of financial statements.

The questions on the right of Table 1 represent the ABET a-k outcomes which are specifically targeted by the program assessment plan. Student responses covered a 1-5 scale with 5 being strongly agree, 4 agree, 3 neutral, 2 disagree, and 1 strongly disagree.

Figure 4 summarizes the comparative results between the two sections. In general, the responses matched well with the exception of question eight (depreciation and taxes) and nine (inflation, purchasing power, real and actual dollars). As will be seen in the discussion on actual test results, these did not show significantly different test performance results. It should also be noted that these were the final two topics covered during the course.

Figure 5 presents the overall score on the embedded final exam questions by section and learning objective. When contrasting this graph with the student survey results in Figure 4, it is consistent in showing the lower confidence in learning objectives 8 and 9. Objective 7, although not an area of student low student confidence in the survey, was not a high score area in the final exam. None of these results in Figure 5 show a statistically significant difference between online and face to face courses at the $95 \%$ confidence level. However, objective 9 test scores were different at the $93 \%$ level.

Table 2 contains questions related to the general operation of the two courses. Questions 22-25 were asked of both sections while questions 26-28 were only asked of the online section. Question 22 was in a format which requires a numerical value for the hours of study per week required. For Question 22, responses for the online section averaged 5.1 hours per week while the online group indicated an average of 5.5 hours per week. Question 27 regarding attendance at Centra sessions had response options ranging from 5 always to 1 never. The remaining questions in Table 2 had the same scale as noted above with 5 strongly agree to 1 as strongly disagree, 3 being neutral. 


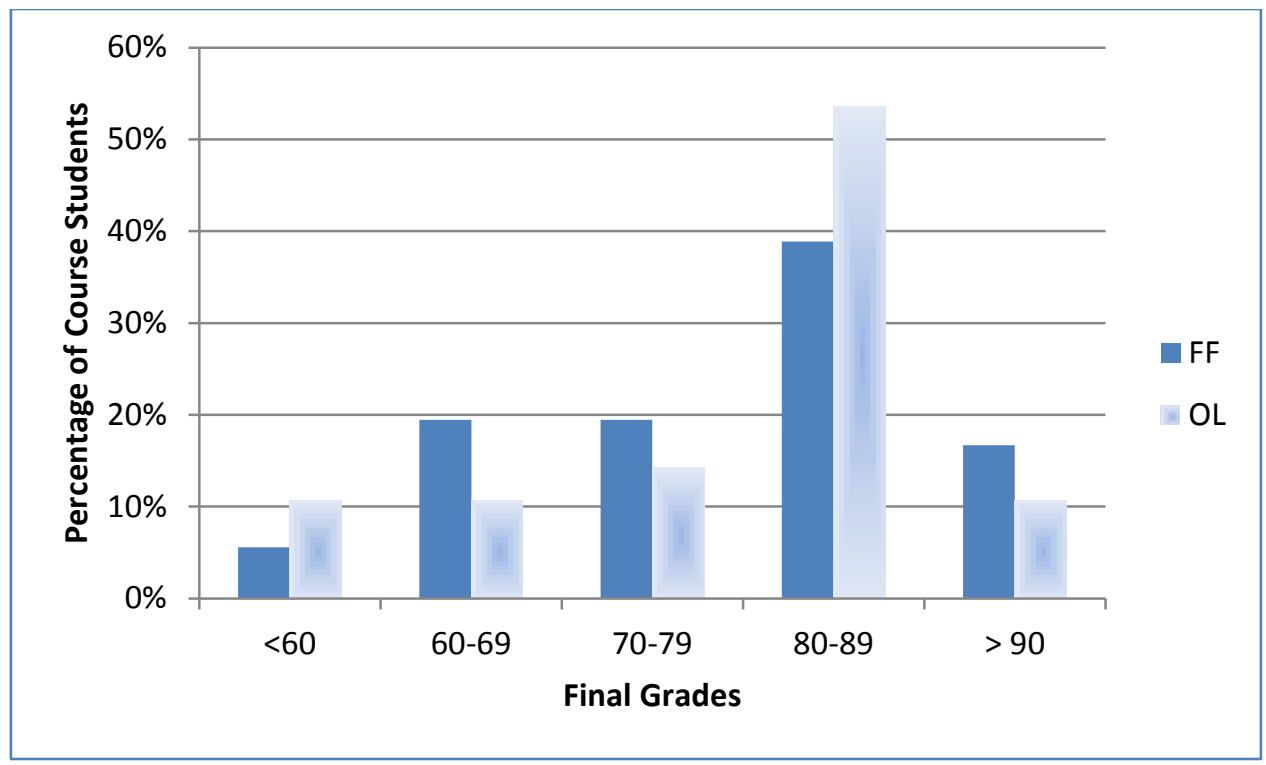

Figure 3: Final Grade Distribution.

Table 1: Student Survey Questions Common to Both Sections.

\begin{tabular}{|c|c|}
\hline Learning Objective Questions & ABET Assessment Plan \\
\hline $\begin{array}{l}\text { 1. I am able to analyze fixed and variable costs including break even } \\
\text { calculations and overhead cost allocation. } \\
\text { 2. I am able to Apply cost estimating methods such as cost indices, learning } \\
\text { curves, sizing scale factors, per unit, and segmented approaches. } \\
\text { 3. I am able to describe the type of information in balance sheets and income } \\
\text { statements and use this to analyze important financial ratios. } \\
\text { 4. I am able to perform compound interest calculations using nominal and } \\
\text { effective interest rates including continuous compounding. } \\
\text { 5. I am able to analyze project and investment alternatives using the } \\
\text { concepts of equivalent cash flows: present, annual and future worth. } \\
\text { 6. I am able to apply the principles and methods of discounted cash flows to } \\
\text { value project and investment alternatives. } \\
\text { 7. Evaluate engineering project and investment alternatives using rate of } \\
\text { return methods such as IRR, B/C analysis, and payback period. } \\
8 \text { I am able to analyze various methods of depreciation and influence of } \\
\text { depreciation on investment tax alternatives. } \\
\text { 9. I am able to analyze the impact of inflation (real and actual dollars) in } \\
\text { project analysis and use price index methods (CPI for example) to reflect } \\
\text { these changes. } \\
\text { 10. I am able to use integrated spreadsheet software (excel) to solve } \\
\text { engineering economics problems. } \\
\text { 11. I am able to analyze global, societal, and ethical issues related to } \\
\text { choosing approaches to solve engineering problems. } \\
\text { 12. I am able to function effectively on a project team to solve an } \\
\text { engineering problem and write a report. } \\
\text { 13. I am able to communicate effectively using business memos and research } \\
\text { papers. }\end{array}$ & $\begin{array}{l}\text { 14. I am able to identify, formulate and solve } \\
\text { engineering economics problems. } \\
\text { 15. I have improved my written communications } \\
\text { skills through this course. } \\
\text { 16. I have improved my understanding of } \\
\text { contemporary issues related to engineering } \\
\text { economics. } \\
\text { 17. I have improved my ability to design a } \\
\text { system, component, or process to meet desired } \\
\text { needs. } \\
\text { 18. I have improved my ability to function on } \\
\text { multidisciplinary teams. } \\
\text { 19. I have improved my understanding of } \\
\text { professional and ethical responsibility. } \\
\text { 20. I have improved my understanding of the } \\
\text { impact of engineering solutions in a global and } \\
\text { societal context. } \\
21 . \text { I have improved my ability to apply } \\
\text { mathematics, science and engineering principles. }\end{array}$ \\
\hline
\end{tabular}




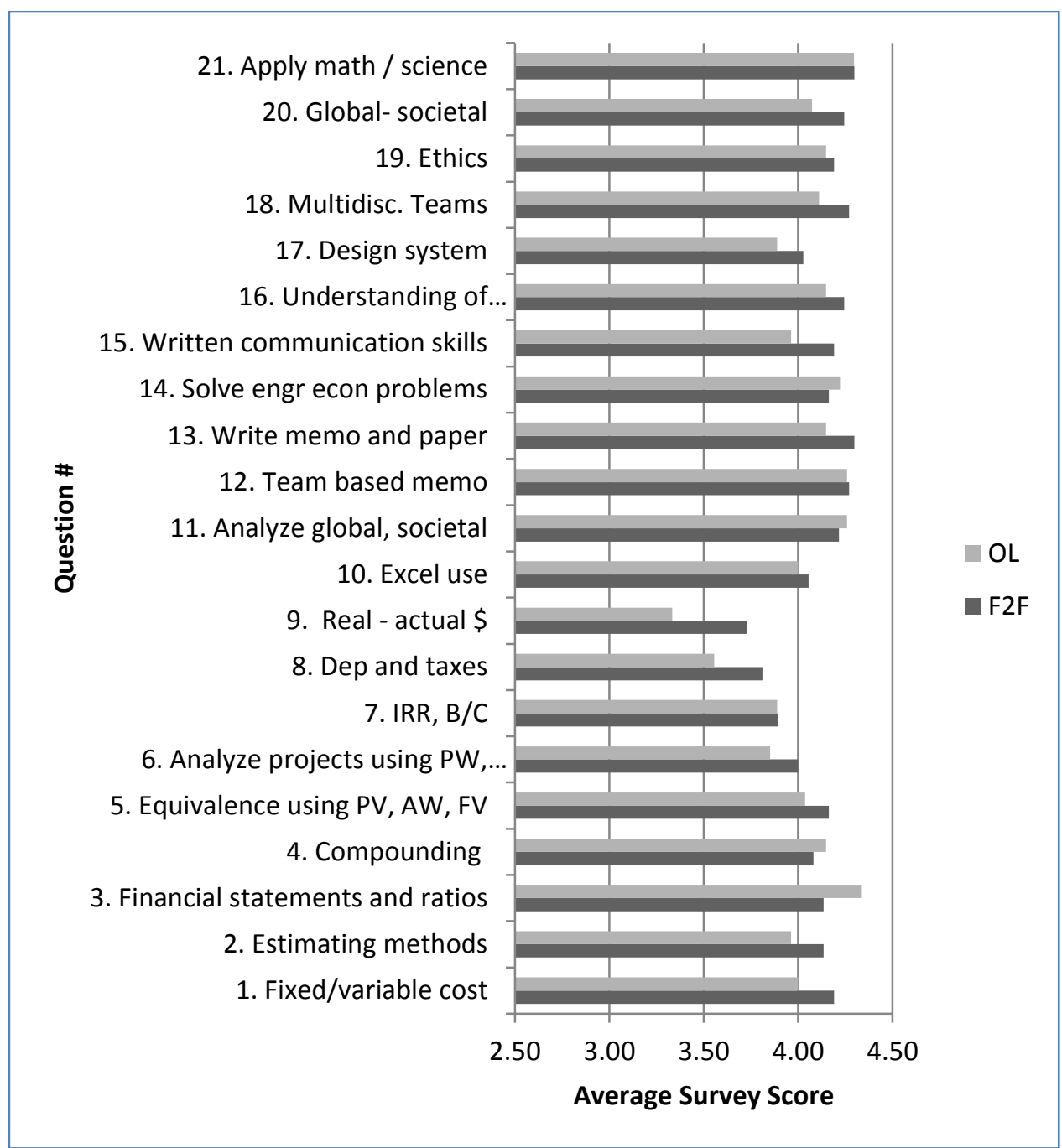

Figure 4: Summary of Student Assessment Question Responses.

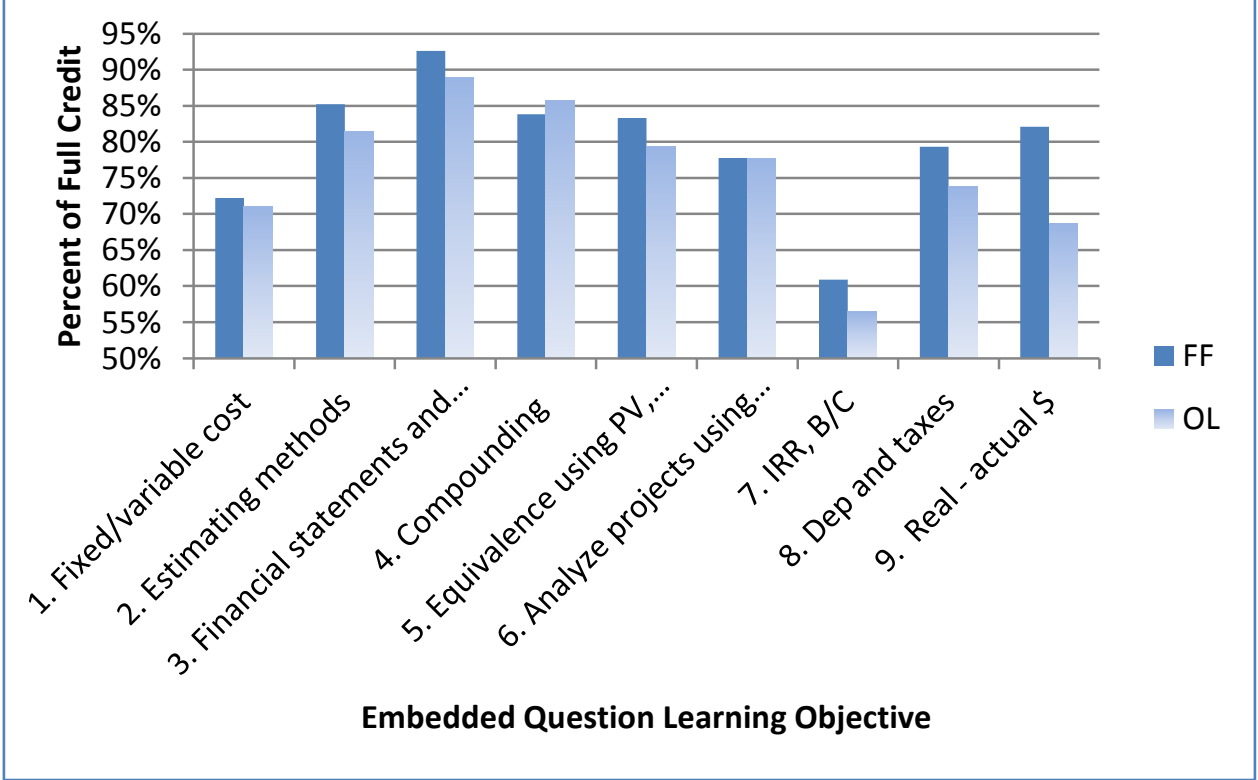

Figure 5: Percent Embedded Question Score by Learning Objective. 
Table 2: Survey Questions related to General Course Issues.

$$
\text { General Class Organization Questions }
$$

22. About how many hours per week on average did you spend preparing, studying, or doing assignments for this course?

23. Please rate the textbook used in the course: I found the textbook was a valuable resource for this course.

24. The instructor was effective in teaching the subject matter of this course.

25. The end of chapter quizzes (Respondus) were useful in helping me evaluate my chapter knowledge.

26. The online format for this course including the videos was effective in learning the materials.

27. How often did you attend the Centra help / discussion sessions? (5- always, 1 never) 28. I learned as much in the online section as I would have in a face to face traditional section.

Analysis of questions 23-25 is contained in Figure 6 and this highlights a statistically significant difference ( $\mathrm{p}<0.01)$ in the perception of the usefulness of the end of chapter quizzes (question 25). The face to face section was very positive but the online section had 30\% (8 of 27) of the class that was negative or very negative on the usefulness of these quizzes. Figure 7 further expands the responses to this question and shows that over $90 \%$ of the face to face section was positive or neutral about the online chapter quizzes while only $70 \%$ of the online section was positive or neutral about these quizzes.

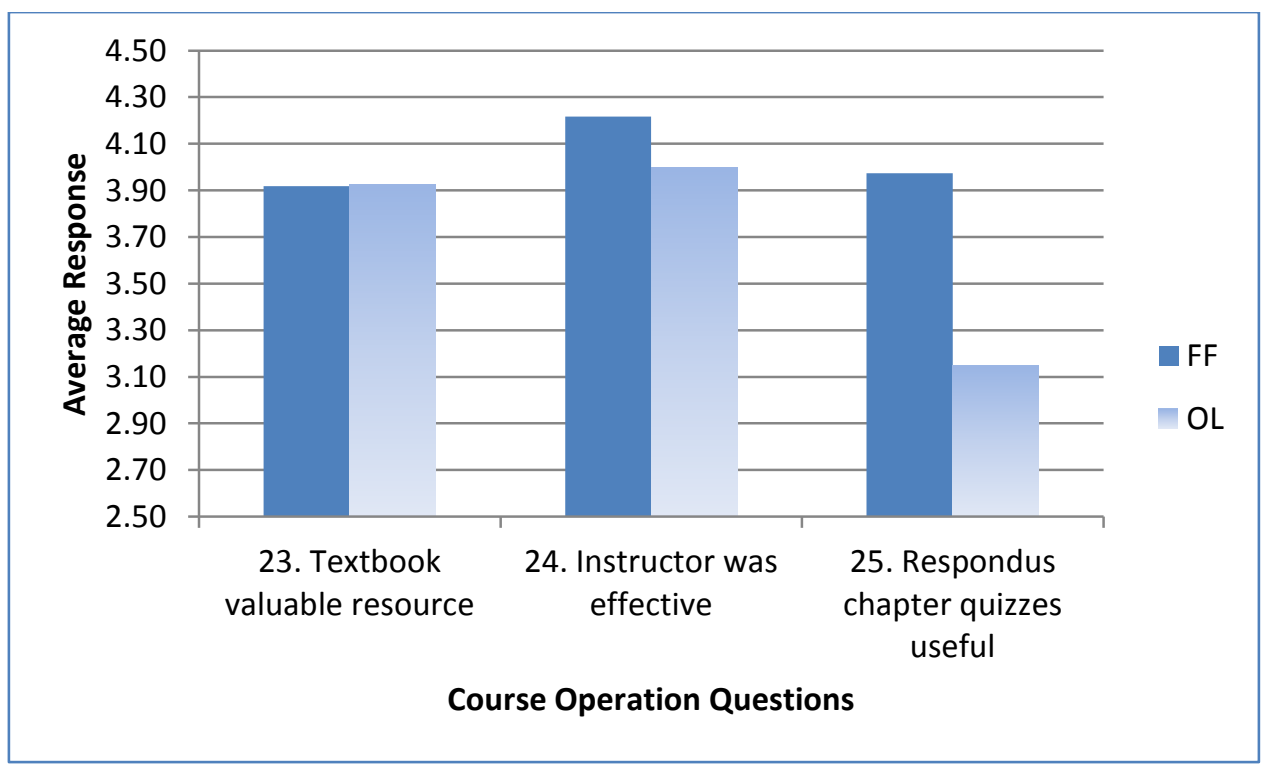

Figure 6: Comparison of Course Analysis Questions. 


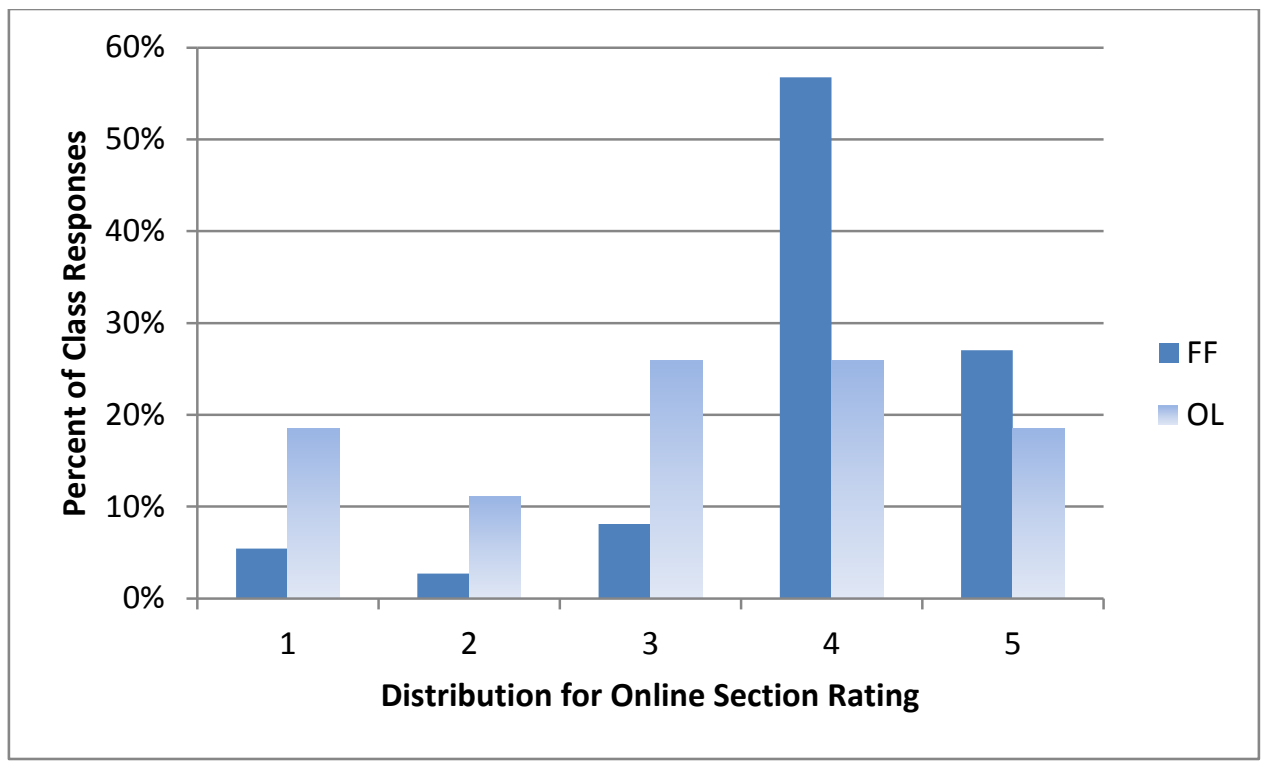

Figure 7: Distribution of Responses for Question 25- Chapter Quizzes.

Questions 26-28 in Table 2 were only asked of the online section and results of these responses are presented in Figure 8. Scores were acceptable but lower than hoped for (especially question 28) considering typical student response to these surveys and the fact that the grade distribution and level of learning was equivalent by all measures. Close analysis of the 27 responses shows a group of 8-9 students who did not respond positively to the online environment while 12 students were consistently positive about these three questions.

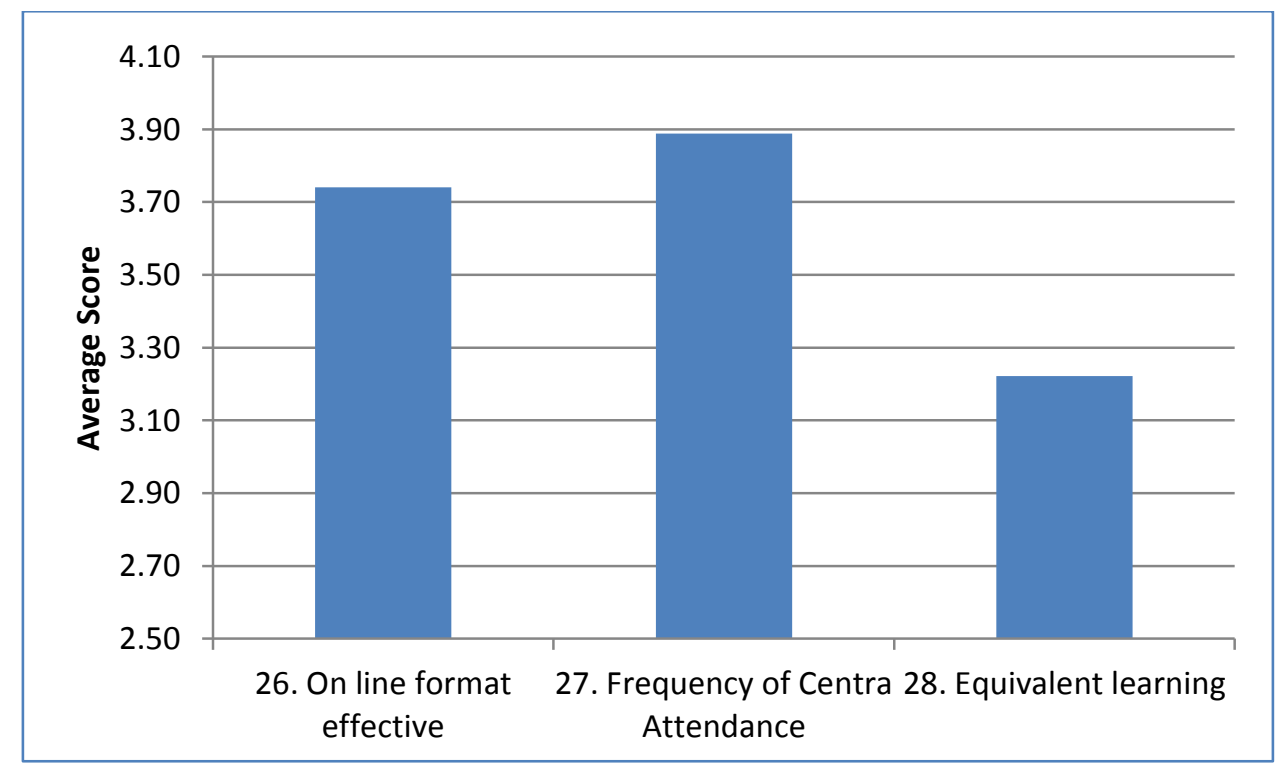

Figure 8: Online Course Question Response.

To further explore the relationship between these three answers and to determine whether the low rating of the online chapter quizzes was also a part of this general low response trend, 
correlation coefficients for these questions were investigated. Results are shown in Table 3 with statistically significant correlations between (quizzes- video format), (quizzes -learning), and (format- learning). In general for 30\% of the online class students (8-9 students), if you did not like the videos, you did not like the quizzes (respondus) and believed your learning was not as much as if you were in a face to face class. On the other hand for $45 \%$ of the class (12 students) there was a positive relationship in that all were answered with a high value (4 or 5).

Table 3: Correlation Coefficients for Online Course Questions 25-28

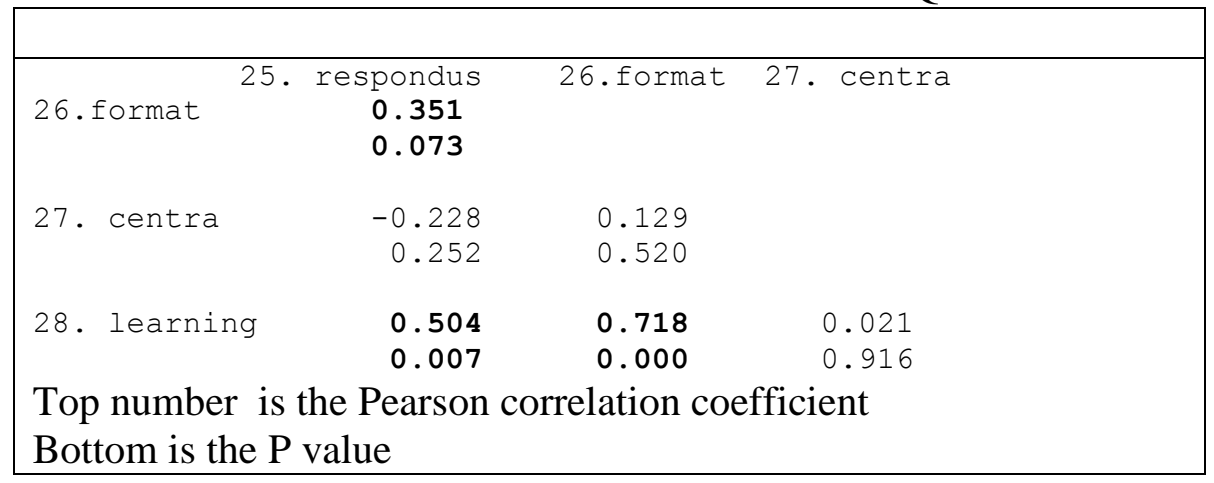

\section{Discussion and Conclusions}

The overall conclusions indicate that the two sections were comparable in almost all aspects (e.g., final course grades, student assessment of learning objectives, student assessment of ABET student outcomes, final exam questions). The only statistically significant differences were the embedded final exam question assessment of inflation (at the 93\% confidence level, but not at the $95 \%$ confidence level) with the online section being lower than the face to face section, and the student assessment of the online chapter quizzes with the online section being lower than the face to face section. The final course grades were slightly lower for the online section when compared to the face to face section, but not statistically significant. These results are consistent with prior published results ${ }^{11,12,13}$.

With regards to the additional survey questions for the online section, approximately $30 \%$ of the online section students had negative responses for the online chapter quizzes. These same students then had a much more likely negative response on questions 26-28 regarding the online format, online attendance, and equivalent learning. However, the same consistency was shown for the approximately $45 \%$ of the online section students who had positive responses for the online chapter quizzes. These students then had a much more likely positive response on questions 26-28.

Future work includes comparing the sections using students' overall GPAs and repeating the analysis over multiple semesters to determine if the online delivery can be perfected to ensure equivalent learning (both actual based on embedded test and exam questions and perceived based on student survey responses). In addition, future work includes surveying students before and after the course with regards to both the course content and the personal interactions. 


\section{Bibliography}

1. Bourne, J., Harris, D., Mayadas, F., “Online Engineering Education: Learning Anywhere, Anytime," Journal of Engineering Education, 94(1), 131-146, 2005.

2. Holdhusen, M., "A Comparison of Engineering Graphics Courses Delivered Face to Face, Online, Via Synchronous Distance Education, and in Hybrid Formats," Proceedings of the 2009 ASEE Annual Conference.

3. James-Byrnes, C.R., Holdhusen, M., "Online Delivery of a Project-Based Introductory Engineering Course," Proceedings of the 2012 ASEE Annual Conference.

4. Osorno, B., "Online Teaching of Electrical Power Systems in Electrical Engineering; Experiences and Myths," Proceedings of the 2007 ASEE Annual Conference.

5. Silcox, G.D., "Comparison of Students' Performance in Online and Conventional Sections of Engineering Thermodynamics," Proceedings of the 2004 American Society for Engineering Education Annual Conference \& Exposition.

6. Whiteman, W., “A Survey of Distance Learning Programs that offer a Master's of Science in Mechanical Engineering Degree," Proceedings of 2012 ASEE Annual Conference.

7. Ozelkan, E., Galambosi, A, “Assessing Engineering Management Students' Perception of On-line Learning," Proceedings of 2009 ASEE Annual Conference.

8. Allen, I.E., Seaman, J., "Sizing the Opportunity: The Quality and Extent of Online Education in the United States, 2002 and 2003," Needham, Mass.: Sloan-C, 2003. Available at: [http://www.sloanc.org/resources/sizing_opportunity.pdf]. Accessed Dec. 28, 2012.

9. NSF Report. Available at: [http://www.nsf.gov/statistics/nsf11316/pdf/tab5.pdf]. Accessed Dec. $28,2012$.

10. U.S. Department of Education, Office of Planning, Evaluation, and Policy Development. Evaluation of evidence-based practices in online learning: A meta-analysis and review of online learning studies. Washington, DC: U.S. Department of Education, Office of Planning, Evaluation and Policy Development, 2010.

11. Peercy, P.S., Cramer, S.M., "Redefining Quality in Engineering Education Through Hybrid Instruction," Journal of Engineering Education, 100(4), 625-629, 2011.

12. Mackey, K.R.M., Freyberg, D.L., "The Effect of Social Presence on Affective and Cognitive Learning in an International Engineering Course Taught via Distance Learning," Journal of Engineering Education, 99(1), 23-34, 2010.

13. On, P.-W., Occena, L., "Instructor's Perspectives of Transforming a Traditional Engineering Economics Course into a Fully Online Delivery," Proceedings of the 2012 ASEE Annual Conference.

14. Elizandro, D.W., Matson, J.O., "Taking a Moment to Teach Engineering Economy," The Engineering Economist, 52(2), 97-116, 2007.

15. Hartman, J. C., "Suggestions For Teaching Engineering Economy at the Undergraduate Level," The Engineering Economist, 44(1), 110-125, 1999.

16. Eschenbach, T.G., "Suggestions for Teaching Engineering Economy at the Undergraduate Level," The Engineering Economist, 44(1), 126-128, 1999.

17. Eschenbach, T.G., "The Engineering Economy Course of 2020," Proceedings of the 2002 American Society for Engineering Education Annual Conference \& Exposition.

18. Peterson, W.R., Landaeta, R.E., Magary, B., "Is It Time For A New Paradigm?," Proceedings of the 2005 American Society for Engineering Education Annual Conference and Exposition.

19. Grasman, S.E., "Teaching Engineering Economics via Distance Education," Proceedings of the 2002 American Society for Engineering Education Annual Conference \& Exposition.

20. Hartman, J.C., Smith, J., "Developing an Online Undergraduate Engineering Economy Course," American Society for Engineering Education, 2010.

21. Pagliari, L., Dixon, E., Kauffmann, P., Mehta, M., “A Distance Education Graduate Course in Engineering Economics: Results and Lessons Learned,” American Society for Engineering Education, 2006. 